\title{
Modeling Departure Time of Students on Public Transports in Yogyakarta, Indonesia
}

\author{
Muhammad Zudhy Irawan (Corresponding author) \\ Graduate School of Engineering, Kyushu University \\ 744, Motooka, Nishi-ku, Fukuoka, Japan, 819-0395 \\ Tel: 81-92-802-3403Ｅ-mail: irawan@civil.doc.kyushu-u.ac.jp \\ Tomonori Sumi \\ Graduate School of Engineering, Kyushu University \\ 744, Motooka, Nishi-ku, Fukuoka, Japan, 819-0395 \\ Tel: 81-92-802-3403Ｅ-mail: sumi@doc.kyushu-u.ac.jp
}

Received: April 18, 2011

Accepted: May 11, 2011

doi:10.5539/mas.v5n4p3

\begin{abstract}
Using the traveler response function to operational feature of transport means, this paper aims to propose a model of departure time decision. The disutility functions relating to the earliness of departure time and lateness of arrival are established here to understand traveler behavior. The model is then applied to identify the morning commute behavior of student in a case study. In particular, it is applied for students using public transports. The numerical result shows that the model well predicts the departure time decision related to travel mode. By 7:15 a.m. as the designated start time at school, an average of 6:14 a.m. with a standard deviation of 10.2 minutes was recognized as the departure time choice for student using public transports.
\end{abstract}

Keywords: Travel behavior, Departure time, Morning commute, Students

\section{Introduction}

The decision of departure time is one of essential elements for travellers in regards to trip planning and execution (Bhat, 1998). These factors are critical in predicting traffic congestion at peak periods as well as broader side congestion analysis and its remedy. Studies regarding departure time where first initiated by Kraft and Wohl (1967). Over the past few decades, this topic was extensively researched (Hendrickson and Kocur, 1981; Chang and Mahmassani, 1988; Mannering et al., 1994; Ettema et al., 2005).

The increased interest in understanding individual behaviour related to departure time decision is a response to the change of transport policy issues from being supply side oriented to demand side oriented (Noland and Polak, 2002). However, several studies in travel demand modelling generally focus on travel behaviour of adults (Koppelman et al., 1993; Hensher and Rose, 2007; Schwanen and Ettema, 2009). More recent studies attempt to understand travel behaviour for children (DiGuiseppi et al., 1998; Yarlagadda and Srinivasan, 2008; Muller et al., 2008). In contrast, studies that focus on adolescent's travel behaviour are very few and mostly new.

Understanding adolescents' travel behaviour becomes crucial since at this age they start to choose their travel mode whether continuing to use the similar mode of travel (bicycle, public transports, or escorted by their household member) or shifting to ride the private vehicle mode. In addition, the short time span in which adolescents have driven private vehicles throughout their lives result in a lower dependence level than adults who have driven for a much longer time span. Due to this, if we intend to reduce the use of private transport and promote widespread the use of public transport, the understanding of adolescents' travel behaviour is essential since the adolescents must be facilitated by the public transport mode.

This research aims to understand the departure time decision of public transport users on commute to school. Senior high school students were chosen as respondents. The reasoning is that they are old enough to have an option to choose their travel mode whether it be using a private vehicle or public transport. A departure time model considering the disutility derived by earliness of home departure time and lateness of arrival time will be proposed in this study. In this model, we attempt to examine traveller response on the characteristic of public transports related to their dynamic travel time.

The plan of this paper is as follows. In the next section we focus on the methodology that is constructed by considering the traveller response on performance of public transport. Section 3 shows the data obtained from either questionnaire survey or field observations. Section 4 applies the proposed model and shows the numerical results. The last section summarizes our results and concludes. 


\section{Methodology}

A utility model, a model that sourced from a principle of utility maximization in microeconomics, became a basic idea in this study. This model assumes that a person will choose an item having the highest utility value (McFadden, 1981). In this study, a disutility model, which is the opposite of utility model, was used to measure disagreement of travelers to the attributes of transport means or the unwillingness derived from their perceptions to specifically temporal constraints. Then the travelers' behavior is expressed based on an assumption that travelers always choose the alternative that offers them minimal disutility. The process is as follows.

\subsection{Traveler behavior}

Students who depart to school have a designated time and place for their classes. If they arrive late at the destination point, they will be penalized for late arrival. Therefore, they have to plan their home departure time to minimize the probability of being late. Since there is a relationship between departure time and penalty for lateness, it can be modelled as a function which depends on trip characteristics for each transport mode such as travel speed, frequency and operation time of public transport.

If $t d_{l}$ is departure time and $t t_{i j}$ is travel time, the arrival time $(t a)$ can be specifically calculated by summing $t d_{l}$ and $t t_{i j}$. However, since travel time varies depending on the operational feature of road vehicles, eventually $t a$ cannot be easily determined as described. Using a probability density function (PDF), $t a$ and $t t_{i j}$ are dependent on departure time $\left(t d_{l}\right)$ and distance $\left(l_{i j}\right)$ from origin $i$ to destination $j$ and can be respectively denoted as $\phi t a$ $\left(\tau \mid l_{i j}, t d_{1}\right)$ and $\phi t t_{i j}\left(\tau \mid l_{i j}\right)$. The PDF of $t a$ is therefore determined by:

$$
\phi t a\left(\tau \mid l_{i j}, t d_{1}\right)=\phi t t_{i j}\left(\tau-t d_{1} \mid l_{i j}\right)
$$

If $t s$ is the designated starting time of school and lateness is defined as a condition where $t a>t s$, the probability of lateness $(\alpha)$ at a given home departure time $t d_{l}$ can be given as:

$\alpha=\int_{t s}^{\infty} \phi t a\left(\tau \mid l_{i j}, t d_{1}\right) d \tau=\int_{t s}^{\infty} \phi t t_{i j}\left(\tau-t d_{1} \mid l_{i j}\right) d \tau=\int_{-t d_{1}}^{\infty} \phi t t_{i j}\left(\tau \mid l_{i j}\right) d \tau$

Since the students are penalized if they late arrive at the school, they will minimize its penalty by leaving home early. This behaviour can thus be formulated as a function of lateness probability $\left(D_{l}=f(\alpha)\right)$.

Further, since the school starting time is designated, students generally would like to depart from their home as late as possible in the morning. Defining the earliest acceptable departure time as the reference point $\left(t d_{e}\right)$, students will obtain a gain when they depart from the origin $\left(t d_{2}\right)$ after $t d_{e}$ and a loss before $t d_{e}$. Using a simple linier function, a function due to the earliness of home departure time $\left(D_{2}\right)$ can be expressed by:

$$
D_{2} \begin{cases}0 & \text { if }\left(t d_{2} \geq t d_{e}\right) \\ \omega\left(t d_{e}-t d_{2}\right) & \text { if }\left(t d_{2}<t d_{e}\right)\end{cases}
$$

In this case, the gain that will be obtained by the students is assumed to be zero illustrating that they do not feel disutility if they depart later than earliest acceptable departure time.

Referring to the two disutility values above, $D_{l}$ and $D_{2}$, derived from the morning trip, it is depicted that students want to depart from home as late as they can, but in the other side they do not want to arrive late at the destination point. We thus can conclude that students decide the optimum departure time which has the minimum value on both disutility values $\left(t d=t d_{12}\right)$. This can be accurately found by summing the derivative between the two given by:

$$
t d=\partial D_{1} / \partial t d_{1}+\partial D_{2} /\left.\partial t d_{2}\right|_{t d=t d_{12}}
$$

\subsection{Transportation System}

To validate our estimated departure times, we compare between simulated and observed arrival times at the destination place. First, it is obvious that the effect of departure time decision at origin- $i$ on arrival time at destination- $j$ is highly dependent on traffic condition from $i$ to $j$.

Given an $l_{i j}$ distance section and a travel speed of $v_{i j}$, it is clear that travel time can be determined as $t t_{i j}=l_{i j} / v_{i j}$. However, since travel speed varies during every time interval, we can use the probabilistic distribution to depict these travel speed fluctuations. Considering $v_{i j}$ is always positive, the distribution of travel speed $v_{i j}$ (denoted as $\Phi\left[v_{i j}\right]$ ) is then calculated by following a log normal distribution (Ang and Tang, 1975) as shown by:

$$
\Phi\left[v_{i j}\right]=\frac{1}{v_{i j} \cdot \sigma\left[v_{i j}\right] \cdot \sqrt{2 \pi}} \exp \left(-\frac{1}{2}\left(\frac{\ln v_{i j}-\mu\left[v_{i j}\right]}{\sigma\left[v_{i j}\right]}\right)^{2}\right)
$$

where $\mu$ and $\sigma$ are the average and standard deviation of $\ln \left(v_{i j}\right)$ at a given time interval respectively. After the distribution of travel speed is known, PDF of travel time can be easily determined as follows:

$$
\phi t t_{i j}\left(t t_{i j} \mid l_{i j}\right)=\phi\left(l_{i j} / t t_{i j}\right)\left|\frac{d v_{i j}}{d t t_{i j}}\right|=\frac{l_{i j}}{t t_{i j}^{2}} \phi\left(l_{i j} / t t_{i j}\right)
$$


Thus, by substituting Eq. (6) into Eq. (2), the value of $\alpha$ can be calculated at every departure time.

Considering $t t_{i j}$ in Eq. (6) represents the total travel time from door to door, for public transport users, total travel time can be expressed by (see Figure 1):

$$
t t_{i j}=t t_{a c}+t t_{w}+\sum t t_{r(x)}+t t_{e g}
$$

where $t t_{a c}$ is access travel time, $t t_{w}$ is public transport waiting time, $t t_{r}$ is riding travel time, $t t_{e g}$ is egress travel time, and $x$ is the number of sections dividing bus route.

Assuming that the student departs from home at $t=t d$ along $l_{a c}$, the PDF of arrival time at the place where he/she boards the public transport (denoted as $\phi t a_{a c}$ ) is given by:

$$
\phi t a_{a c}\left(t \mid t d, l_{a c}\right)=\phi t t_{a c}\left(t-t d \mid l_{a c}\right)
$$

where $t t_{a c}$ is the access travel time obtained by observation and is log normally distributed due to consideration that travel speed is always greater than zero.

The unpunctuality of bus arrival time and no schedule of paratransit arrival time cause difficulties in determining an exact arrival time, therefore the waiting time is also difficult to determine. It is important to note that several studies indicate that waiting time, in reality, is perceived more inconvenient than travel time (Hensher, 1977; Alvarez et al., 2007). Therefore, waiting time cannot be assumed to be negligible. To simplify this problem, we assume that passengers are familiar with the time when the bus/paratransit is usually passing at the boarding location (bus stop). By this, we thus calculate the probability of a passenger to ride on $b^{\text {th }}$ bus at $u^{\text {th }}$ bus stop $\left(P_{b}^{u}\right)$.

Since $\phi t a_{a c}$ is known from Eq. (8) and arrival/departure time of $b^{\text {th }}$ bus at $u^{\text {th }}$ bus stop has also known from field data (denoted as $t d_{b}{ }^{u}$ ), denoting the number of available buses as $B$, the probability that a passenger can board the $b^{\text {th }}$ bus at the $u^{\text {th }}$ bus stop $\left(P_{b}{ }^{u}\right)$ is derived by:

$P_{b}^{u}\left(t d, l_{a c}\right)=\prod_{b=1}^{B}\left(1-P_{b-1}^{u}\right) \int_{-\infty}^{\infty} \phi t a_{a c}\left(t \mid t d, l_{a c}\right) \int_{t}^{\infty} \phi t d_{b}^{u}(\tau) d \tau d t$

A very important factor in deciding home departure time is the variation of riding time along the route from origin to destination. To obtain a good estimate of riding time, a route along $l_{x}$ distance will be divided into $x$ road sections (see Figure 1). Total riding time is calculated by summing the riding time along all $x$ road sections during the specific time interval when the vehicle passes on that road section.

First, assuming that a passenger can always board the $b^{\text {th }}$ bus at the $u^{\text {th }}$ bus stop $\left(P_{b}^{u}=1\right)$. Given bus travel time and its PDF along $l_{x l}$ distance as $t t_{r(x l)}$ and $\phi t t_{r(x l)}$ respectively, the PDF of arrival time at point $x 1$ (denoted as $\left.\phi t a_{x l}\right)$ conditional on $l_{x l}$ distance is given by:

$\phi t a_{x 1}\left(t \mid l_{x 1}\right)=\int_{-\infty}^{\infty} \phi t d_{b}^{u}\left(t d_{b}^{u} \mid l_{x 1}\right) \phi t t_{r(x 1)}\left(t-t d_{b}^{u} \mid l_{x 1}\right) d t d_{b}^{u}$

Then, by using above equation, the calculation process is repeated until $x^{\text {th }}$ road section.

Using the same equation for access travel time in Eq. (8), arrival time at school (ta) conditional on bus arrival time at destination bus stop $\left(t a_{x}\right)$ and egress distance to school $\left(l_{e g}\right)$ can be easily determined. However, since there is distribution of travellers' arrival time at each arrival points $\left(t a_{a c}, t a_{x l}, \ldots, t a\right)$, we employ the convolution integration to find the PDF of arrival time at the destination point (observed school) by summing the arrival time distribution at each points of arrival from origin to destination.

By assuming a traveller arrives at school by using the $b^{\text {th }}$ bus, the probability of being late if traveller uses the $b^{\text {th }}$ bus according to Eq. (2) is given by:

$\alpha_{b}=\int_{t s}^{\infty} \phi t a\left(t \mid b, l_{i j}, t d\right) d t$

Then, if we remove the assumed certainty that a passenger can always board the $b^{\text {th }}$ bus at $u^{\text {th }}$ bus stop $\left(P_{b}^{u}=1\right)$ and instead use the Eq. (9) to determine $P_{b}{ }^{u}$, the probability of being late is given as a function of departure time as follows:

$$
\alpha=\sum P_{b}^{u}\left(t d, l_{a c}\right) \cdot \alpha_{b}
$$

\section{Data Analysis}

\subsection{Yogyakarta as a case study}

Yogyakarta is the capital city of the Yogyakarta Province. According its official website, the number of inhabitants was 435,236 persons as of 2005 and its area is $32.5 \mathrm{~km}^{2}$, giving the population density of 13,809 people per $\mathrm{km}^{2}$ (Yogyakarta Statistical Agency, 2007).

There are two principal reasons for selecting this city as study area. The first is in regards to the school commuting behavior as research focus. In Yogyakarta, population groups aged 15 - 19 years old are the second 
largest inhabitant by $10.63 \%$ based on five-year groupings, while the most residents are ranging in age from 20 to 24 by $17.89 \%$ as of 2005 (Yogyakarta Statistical Agency, 2007).

The second reason is the easiness in reaching the destination places by public transports (buses and paratransits). Almost all of existing roads are passed by public transports. There are 16 operated routes from 19 licensed routes of city bus (paratransit) network with the total vehicle allocation is 591 buses, in which the route length varies from $25 \mathrm{~km}$ to $62 \mathrm{~km}$ (Yogyakarta Bureau of Transportation, Communication and Information, 2006). In addition, there are six routes of Trans Jogja bus network since 2008.

\subsection{Questionnaire survey}

Students from Senior High School 1 in Yogyakarta were sampled as respondents. The questionnaire survey was conducted on March $17^{\text {th }}, 2009$. Out of 365 randomly distributed forms, 312 forms $(85.5 \%)$ were recollected effectively. The basic information about respondents is shown in Table 1 . From 312 respondents, $74.36 \%$ were motorcycle users either escorted or self-driven, $11.22 \%$ were bus users, $3.53 \%$ were bicycle users, $8.97 \%$ walked to school, and $1.92 \%$ were escorted by their parents using a car as shown in Figure 2. However, only 35 sets of data will be used due to limits of this research scope that focuses on travel behaviour for public transport users

\subsection{Travel speed survey}

Based on the questionnaire survey, there are six routes and three routes were identified for respondents using paratransit and bus respectively. The selected routes and observing points for those public transports are shown in Figure 3.

A vehicle plate number survey was used to obtain this data. The main work of this method is the recording vehicle plate numbers at each observing point. By checking the passing time of every vehicle with same number at the different points of a section and measuring the distance, a distribution of vehicle travel speeds in different time duration will be obtained. Due to the many observation points, this survey had to be conducted in a span of three days at times with similar morning traffic patterns for those days (Tuesday - Thursday) between June $23^{\text {th }}$ $25^{\text {th }}, 2009$. The observed mean and standard deviation of bus and paratransit travel speed in per 15 minutes in every road section of different routes from 06.00 a.m. to 08.00 a.m. are shown in Table 2 and Table 3 respectively.

The walking speed is also measured to find the arrival time from home to the bus loading point and from the bus alighting point to school. The egress road in front of Senior High School 1 was chosen as the representative point for both the access and egress road. It was found that the average walking speed is $1.01 \mathrm{~m} / \mathrm{s}$ with a standard deviation of $0.14 \mathrm{~m} / \mathrm{s}$.

\section{Model Application and Result}

Applying the above proposed model, the estimated parameters are shown in Table 4. In obtaining those parameters, the calculation process is as follows. First, to express the individual difference in recognition of earliest home departure time $\left(t d_{e}\right)$, the threshold of $t d_{e}$ regarding $D_{2}$ was assumed as a random variable following the normal distribution. It is obvious that if the mean $(\mu)$ and standard deviation $(\sigma)$ are known, the distribution of $t d_{e}$ would be obtained by:

$$
\Phi\left[t d_{e}\right]=\frac{1}{\sigma\left[t d_{e}\right] \cdot \sqrt{2 \pi}} \exp \left(-\frac{1}{2}\left(\frac{t d_{e}-\mu\left[t d_{e}\right]}{\sigma\left[t d_{e}\right]}\right)^{2}\right)
$$

Thus, giving arbitrarily initial values to the parameters of $\omega$ and the mean and standard deviation of threshold $t d_{e}$, $D_{2}$ can be determined for each departure time. It should be noted that we bound the value of $\mu\left(t d_{e}\right)$ from 5:30 a.m. as the earliest possibility of student to leave home until to $7: 15 \mathrm{a} . \mathrm{m}$. as the designated start time at school $\left(5.5 \leq \mu\left(t d_{e}\right) \leq 7.25\right)$.

Looking into $D_{l}$, which represents a function of the probability of being late $(\alpha)$, it could be directly represented by $\alpha$ itself when the penalty of being late is assumed to be 1. According to Eq. (2), where $t t_{i j}$ was recognized from survey data and calculated by Eq. (7), the value of $\alpha$ can be computed also for each minute of departure time.

By minimizing the sum of $D_{1}$ and $D_{2}$ as presented in Eq. (4), the estimated departure time under the usual assumption of disutility-minimizing principle can be achieved. The theoretical distribution of school arrival time of all students is deduced by incorporating the distribution of estimated departure time and the distribution of total travel time. The fitting values of parameters are obtained by iterating the above process so as to minimize the square difference between theoretical distribution and measured distribution as shown in Eq. (14). The comparisons between simulated and observed respondents arrival time at school are displayed from Figure 4 . 
$R=\min \sum_{n}\left(t a_{m(n)}-t a_{o(n)}\right)^{2}$

where $t a_{m(n)}$ and $t a_{o(n)}$ are simulated and observed arrival time of student $n$ respectively.

As shown in Table 4, 6:10 a.m. are identified as the bus users' earliest tolerable home departure time. Thus, by recognizing students' departure time from home and arrival time at school, an average of 6:14 a.m. with a standard deviation of 10.2 minutes was found as departure time choice for student using public transport to school.

To compare whether or not there are significant differences among observed and modeled arrival time distribution, two-sample Kolmogorov-Smirnov tests as presented in Table 5 were conducted yielding the null hypothesis that there are significant differences between simulated and observed arrival time can be rejected at the $99 \%$ confidence level.

\section{Conclusion}

We have successfully developed a departure time decision model of school morning commute based on the travellers response of transport means' operational characteristics. This model considered disutility obtained by student in regards to arrival lateness and over-earliness of departure. The model was calculated using empirical data obtained from a questionnaire survey conducted in 2009 in Yogyakarta, Indonesia.

The observation showed that adolescent students using public transport tend to arrive earlier than the designated starting time at school. This behaviour is different with worker behaviour that tends to arrive at the latest moment before their work starting time (Jou et al., 2008). Meanwhile, the numerical result showed that by 7:15 a.m. as the designated start time at school, an average of 6:14 a.m. was found as the students' home departure time. This result showed the pattern of students' departure time to school and can be used as a consideration in improving public transport service as well as alleviating traffic congestion caused by school commute. For example, by providing the more buses at the specific time when students frequently depart from home to school. By this, it is expected that disutility caused by bus waiting time can be reduced and therefore attracting the private vehicle users to shift to public transports.

Further, by implementing our proposed model on private vehicle users, thus we can compare the travel behaviour between the two. Then, by combining with the common model of travel mode choice such as multinomial logit (MNL) model, we therefore recognize the several factors influencing travel mode choice.

\section{References}

Alvarez, O., Cantos, P., and Garcia, L. (2007). The Value of Time and Transport Policies in A Parallel Road Network. Transport Policy, 14, 366-376, doi:10.1016/j.transpol.2007.04.012, http://dx.doi.org/10.1016/j.transpol.2007.04.012

Ang, A.H-S. and Tang, W.H. (1975). Probability Concept in Engineering Planning and Design. Canada: John Wiley \& Son, Inc.

Bhat, C.R. (1998). Analysis of Travel Mode and Departure Time Choice for Urban Shopping Trips. Transportation Research Part B, 32, 361-371, doi:10.1016/j.tra.2009.05.001, http://dx.doi.org/10.1016/j.tra.2009.05.001

Chang, G.L. and Mahmassani, H.S. (1988). Travel Time Prediction and Departure Time Adjustment Behavior Dynamics in a Congested Traffic System. Transportation Research Part B, 22B, 217-232, doi:10.1016/0191-2615(88)90017-3, http://dx.doi.org/10.1016/0191-2615(88)90017-3

DiGuiseppi, C., Roberts, I., and Li, L. (1998). Determinants of Car Travel on Daily Journeys to School: Cross Sectional Survey of Primary School Children. Br. Med. Journal, 316, 1426-1428

Ettema, D., Tamminga, G., Timmermans H., and Arentze, T. (2005). A Micro-Simulation Model System of Departure Time Using a Perception Updating Model Under Travel Time Uncertainty. Transportation Research Part A, 39, 325-344, doi:10.1016/j.tra.2004.12.002, http://dx.doi.org/10.1016/j.tra.2004.12.002

Hendrickson C. and Kocur G. (1981). Schedule Delay and Departure Time Decisions in a Deterministic Model. Transportation Science, 15, 62-77, doi:10.1287/trsc.15.1.62, http://dx.doi.org/10.1287/trsc.15.1.62

Hensher, D.A. and Rose, J.M. (2007). Development of Commuter and Non Commuter Mode Choice Models for The Assessment of New Public Transport Infrastructure Projects: A Case Study. Transportation Research Part A, 41, 428-443, doi:10.1016/j.tra.2006.09.006, http://dx.doi.org/10.1016/j.tra.2006.09.006

Jou, R.C., Kitamura, R., Weng, M.C., and Chen, C.C. (2008). Dynamic Commuter Departure Time Choice Under Uncertainty. Transportation Research Part A, 42, 774-783, doi:10.1016/j.tra.2008.01.017, http://dx.doi.org/10.1016/j.tra.2008.01.017

Kraft, G. and Wohl, M. (1967). New Directions for Passenger Demand Analysis and Forecasting. Transportation Research, 1, 205-230, doi:10.1016/0041-1647(67)90033-0, http://dx.doi.org/10.1016/0041-1647(67)90033-0 
Koppelman, F.S., Bhat, C.R., and Schofer, J.L. (1993). Market Research Evaluation of Actions to Reduce Suburban Traffic Congestion: Commuter Travel Behaviour and Response to Demand Reduction Actions. Transportation Research Part A, 27, 383-393, doi:10.1016/0965-8564(93)90034-I, http://dx.doi.org/10.1016/0965-8564(93)90034-I

Mannering, F., Kim, S.G., Barfield, W., and Ng, L. (1994). Statistical Analysis of Commuters' Route, Mode, and Departure Time Flexibility. Transportation Research Part C, 2, 35-47, doi:10.1016/0968-090X(94)90018-3, http://dx.doi.org/10.1016/0968-090X(94)90018-3

McFadden, D. (1981). Structural Analysis of Discrete Data with Econometrics Applications. Cambridge: MIT Press.

Muller, S., Tscharaktschiew, S., and Haase, K. (2008). Travel to School Mode Choice Modelling and Patterns of School Choice in Urban Areas. Journal of Transport Geography, 16, 342-357, doi:10.1016/j.jtrangeo.2007.12.004, http://dx.doi.org/10.1016/j.jtrangeo.2007.12.004

Noland, R.B. and Polak, J.W. (2002). Travel Time Variability: A Review of Theoretical and Empirical Issues. Transport Reviews, 22, 39-54, doi:10.1080/01441640010022456, http://dx.doi.org/10.1080/01441640010022456

Schwanen, T. and Ettema, D. (2009). Coping With Unreliable Transportation When Collecting Children: Examining Parents' Behaviour With Cumulative Prospect Theory. Transportation Research Part A, 43, 511-525, doi:10.1016/j.tra.2009.01.002, http://dx.doi.org/10.1016/j.tra.2009.01.002

Yarlagadda, A.K. and Srinivasan, S. (2008). Modelling Children's School Travel Mode and Parental Escort Decisions. Transportation, 35, 201-218, doi:10.1007/s11116-007-9144-6, http://dx.doi.org/10.1007/s11116-007-9144-6

Yogyakarta Bureau of Transportation, Communication and Information (2006). Transportation in Number, Yogyakarta

Yogyakarta Statistical Agency (2007). Yogyakarta in Number: Chapter 4. [Online], Available: http://yogyakarta.bps.go.id/component/content/article/58-sosial/70-sosial (March 22, 2011)

Table 1. Respondents' basic information

\begin{tabular}{|l|llll|}
\hline Age & $\leq 16: 59$ & $17: 151$ & $\geq 18: 102$ & \\
\hline Driving license ownership & Yes: 177 & No: 135 & & \\
\hline Gender & Male: 127 & Female: 185 & & \\
\hline Home to school route distance & $\leq 1: 40$ & $3-4: 35$ & $6-7: 20$ & $9-10: 15$ \\
(in km) & $1-2: 27$ & $4-5: 33$ & $7-8: 29$ & $\geq 10: 41$ \\
& $2-3: 32$ & $5-6: 25$ & $8-9: 15$ & \\
\hline School arrival time & $\leq 6.00: 1$ & $6.20-6.25: 6$ & $6.45-6.50: 32$ & $7.10-7.15: 23$ \\
& $6.00-6.05: 1$ & $6.25-6.30: 14$ & $6.50-6.55: 31$ & $\geq 7.15: 3$ \\
& $6.05-6.10: 0$ & $6.30-6.35: 18$ & $6.55-7.00: 41$ & \\
& $6.10-6.15: 5$ & $6.35-6.40: 29$ & $7.00-7.05: 41$ & \\
& $6.15-6.20: 4$ & $6.40-6.45: 26$ & $7.05-7.10: 37$ & \\
\end{tabular}

Table 2. Temporal variations of bus travel speed

\begin{tabular}{|c|cccccccc|}
\hline \multirow{2}{*}{$\begin{array}{c}\text { Road } \\
\text { Section }\end{array}$} & $6: 00-$ & $6: 15-$ & $6: 30-$ & $6: 45-$ & $7: 00-$ & $7: 15-$ & $7: 30-$ & $7: 45-$ \\
& $6: 15$ & $6: 30$ & $6: 45$ & $7: 00$ & $7: 15$ & $7: 30$ & $7: 45$ & $8: 00$ \\
\hline \multirow{2}{*}{$1-2$} & 30.77 & 27.71 & 28.99 & 29.79 & 28.79 & 28.45 & 31.63 & 30.55 \\
& $(2.20)$ & $(1.27)$ & $(1.45)$ & $(3.52)$ & $(3.34)$ & $(1.50)$ & $(0.37)$ & $(1.31)$ \\
\hline \multirow{2}{*}{$2-3$} & 25.43 & 23.41 & 21.10 & 20.89 & 19.43 & 19.47 & 20.60 & 22.19 \\
& $(0.67)$ & $(1.53)$ & $(2.80)$ & $(2.06)$ & $(1.79)$ & $(1.07)$ & $(2.38)$ & $(3.08)$ \\
\hline \multirow{2}{*}{$3-4$} & 15.52 & 14.21 & 17.61 & 14.78 & 16.02 & 16.57 & 17.36 & 15.81 \\
& $(1.24)$ & $(0.88)$ & $(2.42)$ & $(1.88)$ & $(1.17)$ & $(0.69)$ & $(1.98)$ & $(1.67)$ \\
\hline \multirow{2}{*}{$5-6$} & 14.86 & 15.55 & 12.35 & 11.74 & 11.43 & 14.15 & 13.98 & 12.13 \\
& $(0.39)$ & $(0.98)$ & $(1.94)$ & $(0.96)$ & $(0.51)$ & $(0.91)$ & $(0.67)$ & $(0.87)$ \\
\hline \multirow{2}{*}{$6-3$} & 30.85 & 32.50 & 31.63 & 29.77 & 31.51 & 30.53 & 29.36 & 27.39 \\
& $(2.66)$ & $(2.59)$ & $(1.59)$ & $(4.12)$ & $(2.93)$ & $(0.83)$ & $(2.80)$ & $(2.47)$ \\
\hline \multirow{2}{*}{$7-8$} & 21.54 & 22.66 & 17.76 & 19.18 & 20.28 & 20.89 & 21.30 & 21.44 \\
& $(1.02)$ & $(1.47)$ & $(1.06)$ & $(1.44)$ & $(2.02)$ & $(1.80)$ & $(1.00)$ & $(1.31)$ \\
\hline
\end{tabular}


Table 3. Temporal variations of paratransit travel speed

\begin{tabular}{|c|cccccccc|}
\hline \multirow{2}{*}{ Road } & \multicolumn{7}{|c|}{ Mean (Standard Deviation) } \\
\cline { 2 - 9 } & $6: 00-$ & $6: 15-$ & $6: 30-$ & $6: 45-$ & $7: 00-$ & $7: 15-$ & $7: 30-$ & $7: 45-$ \\
& $6: 15$ & $6: 30$ & $6: 45$ & $7: 00$ & $7: 15$ & $7: 30$ & $7: 45$ & $8: 00$ \\
\hline \multirow{2}{*}{$\mathrm{a}-\mathrm{b}$} & 34.53 & 34.32 & 28.51 & 26.89 & 30.77 & 28.54 & 31.62 & 30.30 \\
& $(4.22)$ & $(5.49)$ & $(0.96)$ & $(1.82)$ & $(2.88)$ & $(2.12)$ & $(2.43)$ & $(2.16)$ \\
\hline \multirow{2}{*}{$\mathrm{b}-\mathrm{c}$} & 29.52 & 25.98 & 18.71 & 15.89 & 17.68 & 22.49 & 21.30 & 19.80 \\
& $(1.74)$ & $(0.66)$ & $(1.84)$ & $(0.95)$ & $(2.22)$ & $(0.59)$ & $(2.38)$ & $(1.92)$ \\
\hline \multirow{2}{*}{$\mathrm{c}-\mathrm{d}$} & 29.03 & 26.43 & 23.54 & 21.48 & 21.83 & 21.55 & 24.11 & 23.24 \\
& $(4.55)$ & $(3.96)$ & $(2.49)$ & $(3.21)$ & $(2.70)$ & $(1.78)$ & $(1.67)$ & $(1.79)$ \\
\hline \multirow{2}{*}{ e-f } & 38.48 & 35.58 & 35.81 & 31.83 & 30.58 & 35.79 & 33.53 & 31.20 \\
& $(1.95)$ & $(5.64)$ & $(5.20)$ & $(3.34)$ & $(4.23)$ & $(4.81)$ & $(3.73)$ & $(4.63)$ \\
\hline \multirow{2}{*}{$\mathrm{f}-\mathrm{d}$} & 27.29 & 28.53 & 26.29 & 24.76 & 24.00 & 27.80 & 25.71 & 25.67 \\
& $(3.78)$ & $(5.38)$ & $(3.26)$ & $(1.26)$ & $(2.42)$ & $(2.84)$ & $(2.80)$ & $(4.13)$ \\
\hline \multirow{2}{*}{$\mathrm{g}-\mathrm{h}$} & 32.07 & 34.79 & 31.05 & 27.60 & 28.33 & 29.44 & 29.78 & 31.04 \\
& $(4.08)$ & $(5.04)$ & $(5.16)$ & $(3.68)$ & $(2.59)$ & $(3.06)$ & $(3.71)$ & $(0.95)$ \\
\hline \multirow{2}{*}{$\mathrm{h}-\mathrm{d}$} & 30.84 & 32.61 & 21.51 & 19.65 & 22.79 & 28.80 & 30.56 & 30.10 \\
& $(3.75)$ & $(2.24)$ & $(3.70)$ & $(2.84)$ & $(1.84)$ & $(2.33)$ & $(2.69)$ & $(1.20)$ \\
\hline \multirow{2}{*}{$\mathrm{i}-\mathrm{h}$} & 27.31 & 30.47 & 28.66 & 22.30 & 27.10 & 30.97 & 23.13 & 24.51 \\
& $(7.13)$ & $(1.96)$ & $(3.76)$ & $(2.93)$ & $(2.07)$ & $(6.29)$ & $(3.04)$ & $(1.82)$ \\
\hline
\end{tabular}

Table 4. Parameter estimation results

\begin{tabular}{|l|c|}
\hline \multicolumn{1}{|c|}{ Variable Description } & Coefficient \\
\hline Parameter of $D_{l}(\omega)$ & 0.63 \\
Average of earliest tolerable departure time $(\mu)$ & $6: 10$ \\
Standard deviation of earliest tolerable departure time (in minute) $(\sigma)$ & 21 \\
Departure time $(\mu)$ & $6: 14$ \\
Standard deviation of departure time (in minute) $(\sigma)$ & 10.2 \\
\hline
\end{tabular}

Table 5. Kolmogorov-Smirnov test statistics

\begin{tabular}{|l|c|c|c|}
\hline \multicolumn{1}{|c|}{ Description } & $\mathrm{n}$ & $\mathrm{K}-\mathrm{S}$ test & $\mathrm{p}$-value \\
\hline Public transport users & 35 & 0.09 & 0.99 \\
\hline
\end{tabular}

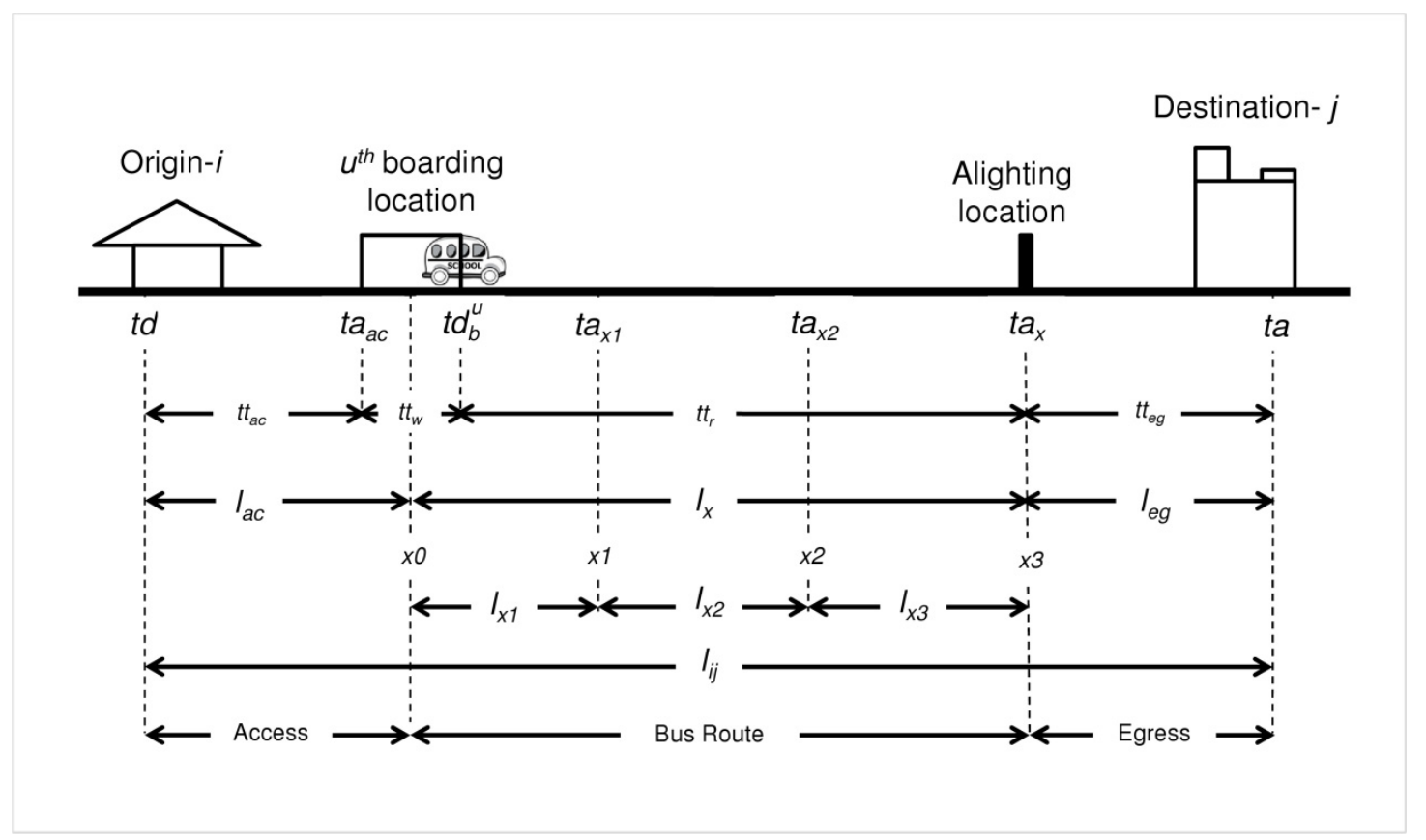

Figure 1. Commuters' travel by public transportation from origin to destination 

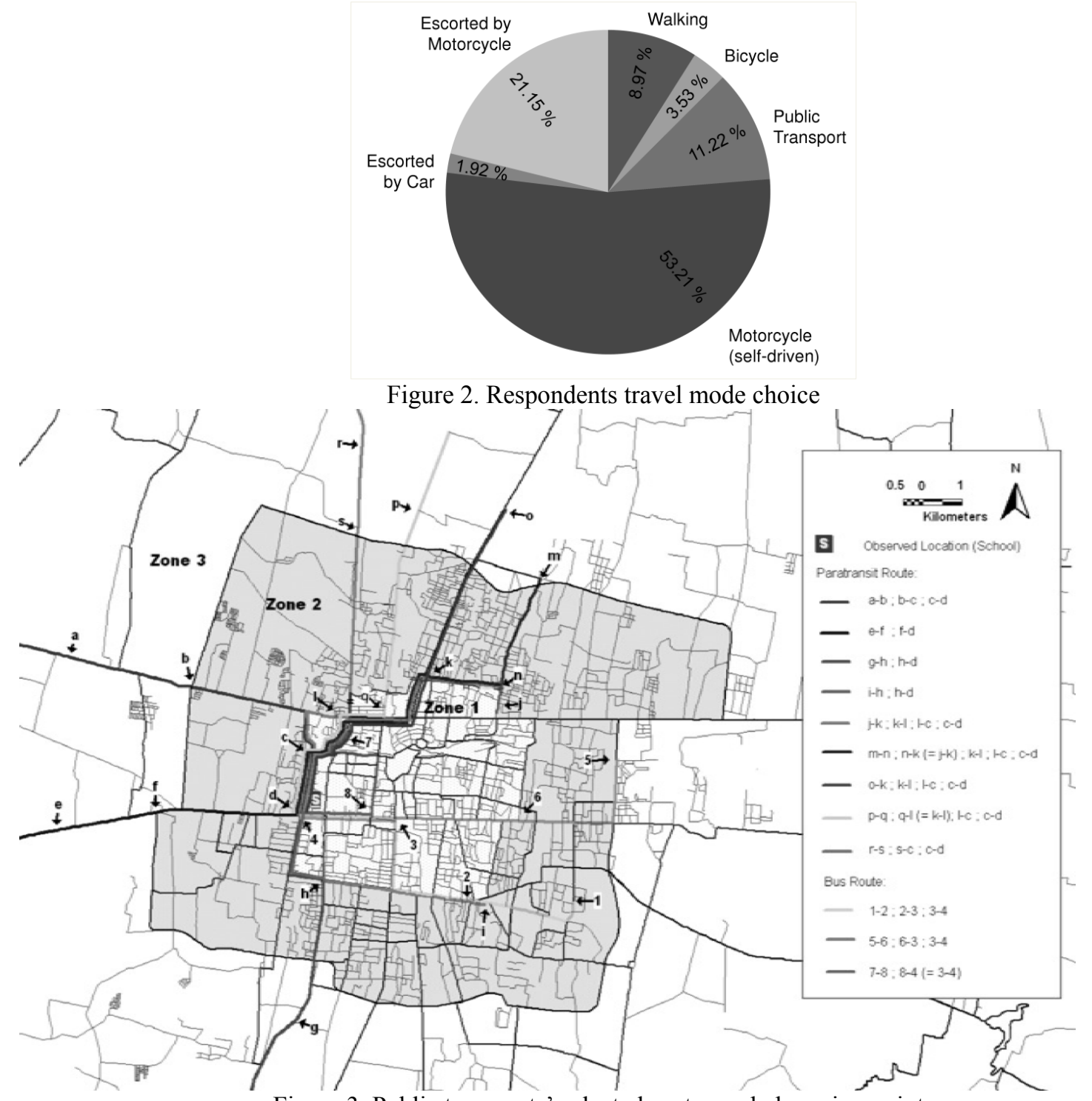

Figure 3. Public transports' selected routes and observing points

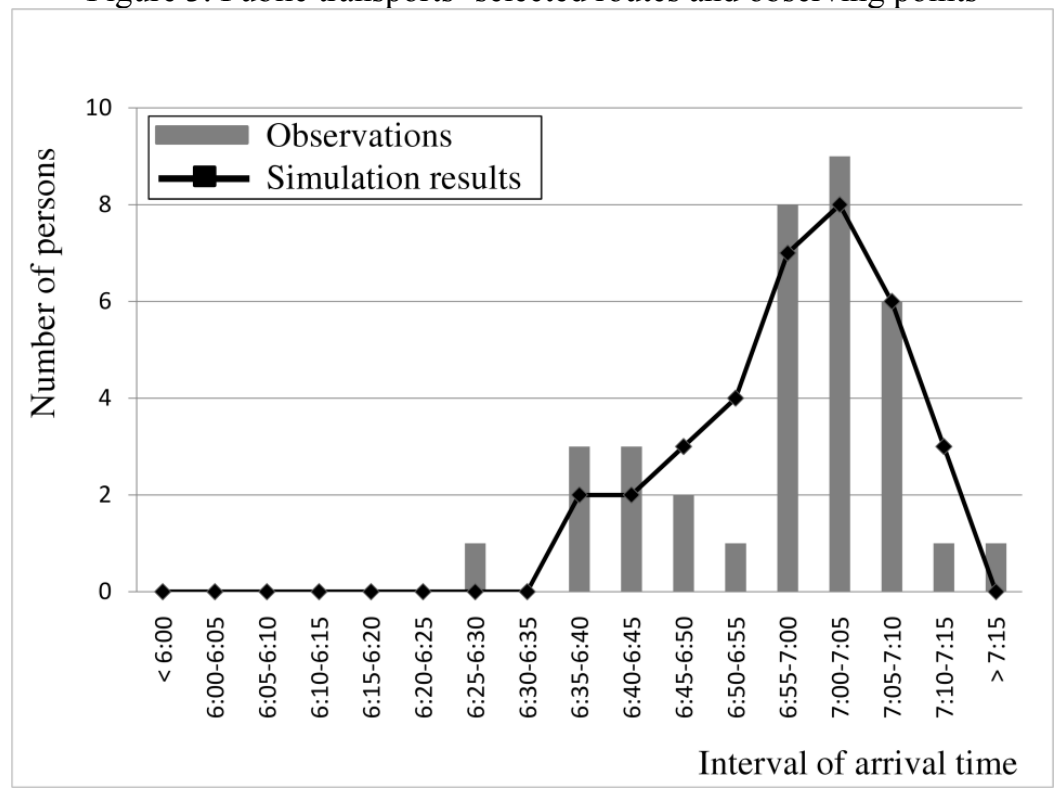

Figure 4. Public transport users' arrival time 